\title{
Direct observation of the behaviour of fish in relation to fishing gear
}

\author{
C. C. Hemmings \\ Marine Laboratory; Aberdeen, Scotland
}

\begin{abstract}
KURZFASSUNG: Direkte Beobachtung des Verhaltens von Fischen in Beziehung zu Fischfanggeräten. Die Wirkungsweise des dänischen Grundschleppens beim Fang wurde von Tauchern vor der schottischen Küste in Tiefen bis zu $40 \mathrm{~m}$ untersucht. Die kontinuierlichen Gestaltsveränderungen des Netzes während des Schleppens ließen Vergleiche zu anderen Grundschleppnetzen zu. Auf Grund der geringen Schleppgeschwindigkeit konnten während des ganzen Fangprozesses Beobachtungen angestellt werden. Dem Verhalten von Schellfisch (Melanogrammus aeglifinus), Sandspierling (Ammodytes spec.), Scholle (Pleuronectes platessa) und Kliesche (Limanda limanda) vor und in dem Schleppnetz wurde besondere Aufmerksamkeit gewidmet. Der gleichzeitige Einsatz von Fotoapparat und Tonbandgerät ermöglichte es jedem Taucher, die Verhaltensweisen der einzelnen Arten mit Zeitangaben festzuhalten. Anderungen der relativen Zahl der Fische, ihrer Schwimmgeschwindigkeit und der Zeit ihres Aufenthaltes vor dem Netz ließen sich mit Anderungen der Netzgestalt, dem Verhalten der Trossen und der Schleppgeschwindigkeit korrelieren. Einige Verhaltensformen, die bei der Orientierung und beim Fang der Fische von Bedeutung sind, werden besprochen.
\end{abstract}

\section{INTRODUCTION}

The concern of gear technologists and fishery biologists working on problems of fish capture is to assess and improve the efficiency of fishing gear. Many of the possible approaches have two aspects: firstly to study the behaviour of the fish by photography, television, acoustic techniques or direct observation, and secondly to study the gear partly by the above methods, but more often by instruments measuring speeds, heights, spreads and tensions of different parts of the gear. The fishing gear can be considered as a complex assemblage of parts giving acoustic and visual stimuli to which fish respond by changes of speed and direction of movement. In a successful gear, these movements result in the capture of the fish.

The full-sized demersal trawl is towed too fast for prolonged study by divers hanging on to the net, although in clear water the gear can be photographed from fixed positions as it is towed past. The Danish seine net is extensively used around the coasts of Scotland, and as it is towed much more slowly divers can hang on to it for most of the haul. This paper is concerned primarily with the behaviour of fish in the mouth of the Danish seine net, and gear performance is mentioned only in so far as it affects behaviour. 


\section{METHODS}

\section{Fishing and diving}

Fishing and diving studies have usually been conducted from F.R.V. "Mara" $(24 \mathrm{~m})$. Some work was also carried out from commercial seine net vessels. In all hauls the technique used was that known as Scottish "fly-dragging", (Thomson 1969),

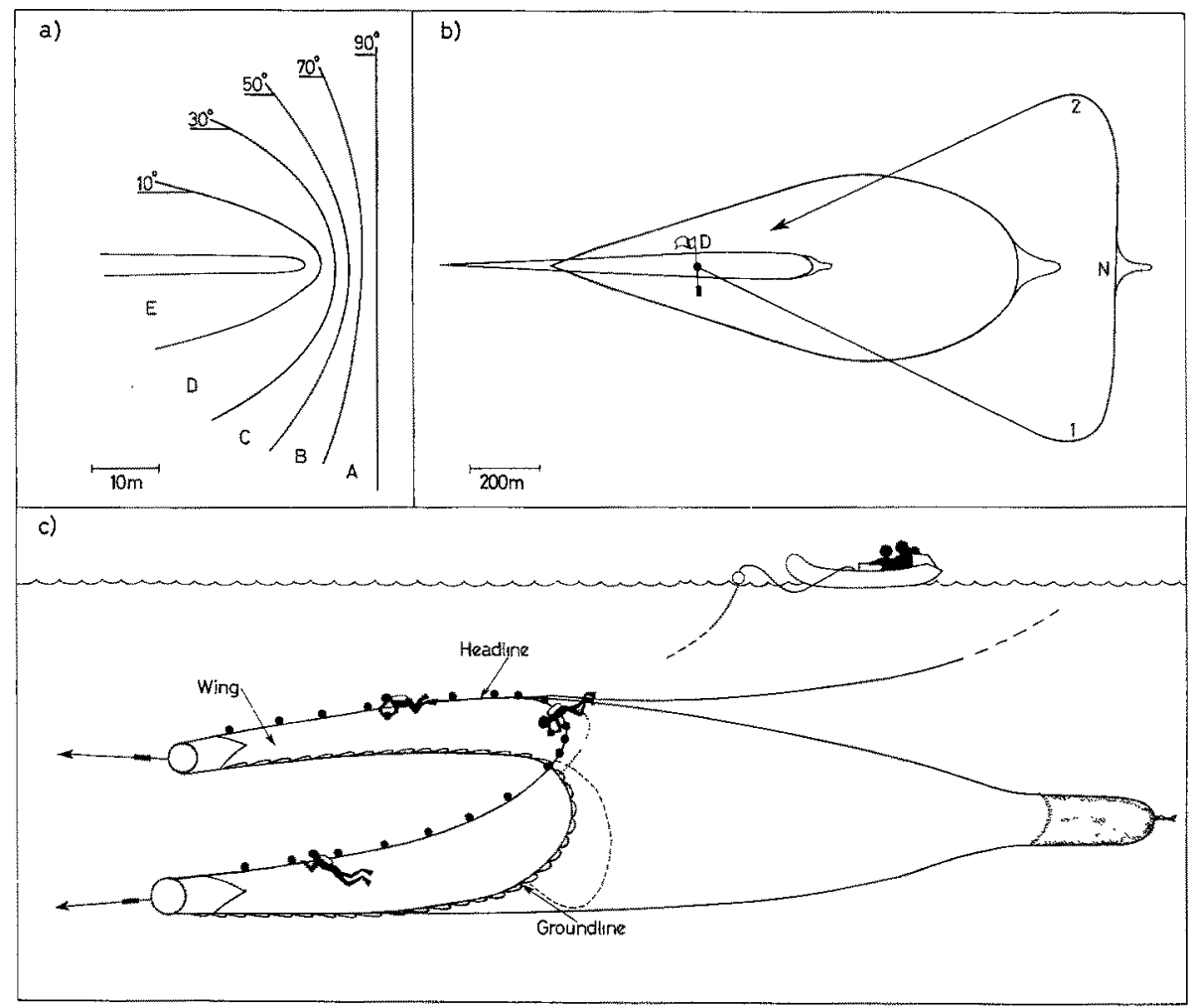

Fig. 1: a Stages of closure of seine net. $b$ Plan view of ropes and net. " $\mathrm{D}$ " is the dhan position where fishing starts, " 1 " the first rope laid, " $N$ " the net position and " 2 " the second rope. Two later stages of hauling are shown when the net has closed to stages $\mathrm{A} / \mathrm{B}$ and. E. $c$ Perspective view of net and diver-observers. Water depth is not to scale in the sketch. Seam lines are marked with broken lines

which is illustrated in Figure 1. The fundamental difference between the trawl and demersal seine net is the change in shape of the seine net that results from the way the ropes are laid out on the sea-bed before hauling commences. There are no spreading devices on the wingends of a seine net. At the start of the haul the wings of the net stretch out in a line, and as it progresses the curvature increases through stages " $A$ " to " $E$ " (Fig. 1a). For the purposes of these studies it was assumed that the curves are catenaries. Figure $1 \mathrm{~b}$ shows the "classic" shape of the seine net ropes when first laid 
out, and the approximate position and shapes of ropes and net at later stages of hauling. The net accelerates continuously throughout the haul for two reasons: firstly as the ropes become straighter the forward component of movement becomes greater; secondly the rate of rope hauling is progressively raised by increasing the hauling rate on the vessel's winch.

Conventional compressed air diving techniques were used and they, together with safety and operational procedures, are described in greater detail by HEMmings (1972). Most hauls were carried out with three divers on the net, and Figure 1c shows their typical position. The net was always followed by an inflatable rubber boat with a telephone communication cable to the diver at the centre of the headline. Fishing was usually conducted at depths between 20 and $25 \mathrm{~m}$, where it was hoped that the appropriate species of fish would be found. However, on occasions it was necessary to work considerably deeper, to a maximum of $40 \mathrm{~m}$. Naturally this greater depth severely restricted the frequency and duration of dives for decompression reasons.

\section{Recording information}

Each diver was equipped with a tape-recorder and either a still or cine-camera. Because it was only found possible to concentrate attention on either photography or voice-recording, the results from an individual dive tended to be in one of two forms: either an extensive taped commentary supported by a number of photographs, or a longer series of photographs with some additional information on tape of the subject and the time when each exposure was made. Although fish were often present in considerable numbers, it was soon found that to describe the activity of a number of fish together did not produce a record that could be analysed quantitatively. The only satisfactory way was to pick an individual fish and give a commentary on it until it passed out of sight. In this way the behaviour of a group was built up from individual observations. This method was used for studying flatfish (Pleuronectidae), and haddock (Melanogrammus aeglefinus). Sandeels (Ammodytidae) formed such tight and cohesive schools that to pick individuals was impossible and in this case the school itself formed the unit described.

The recording of a synchronised start time on all tapes allowed comparisons to be made of events within and between hauls. Each float along the $60 \mathrm{~m}$ headline was numbered, so that the position where observations were made or photographs taken was known. Transcription of the tape-recordings was carried out as soon as possible after the dive in order that verbal ambiguities could be eliminated and supplementary information added whilst still fresh in the diver's mind. Further details of the communication, recording and photographic techniques are given by HEMmings (1972).

The groundline of the net had a series of $10 \mathrm{~cm}$ white scale marks at $1 \mathrm{~m}$ intervals along its length. It was required that photographs should as far as possible be taken vertically downwards to include at least one of the scale marks. This allowed the following information to be calculated from most photographs: (1) Number of fish/ area, (2) size of fish, (3) distance of each fish in front of groundline, (4) angle of attack of the gear, (5) angle of orientation of fish to gear, (6) angle of orientation of fish to direction of movement and (7) ground speed. 


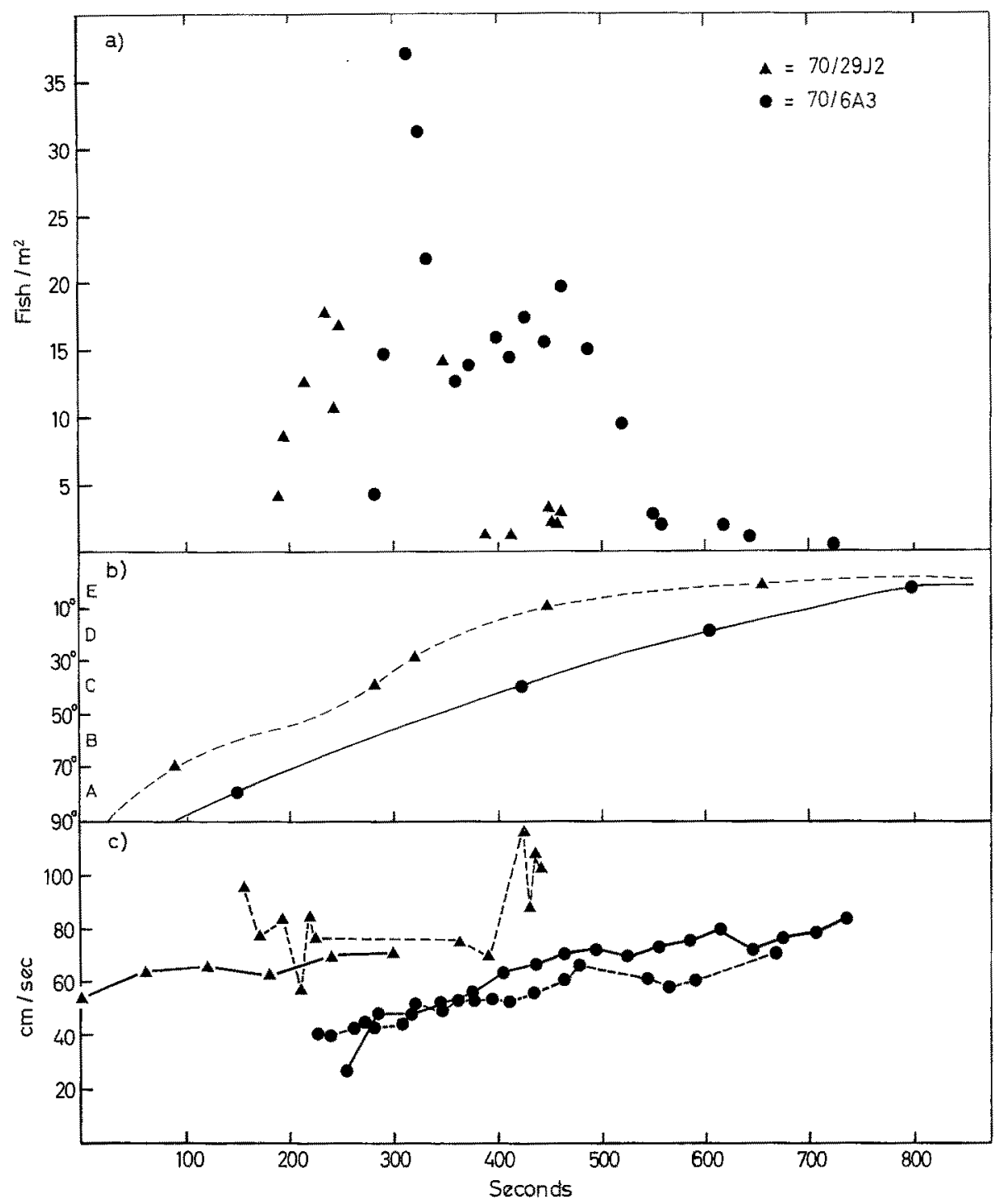

Fig. 2: $a$ Density of flatfish at the centre of the groundline on two hauls. $b$ Stages of closure of che net on the same two hauls. $c$ Water speed (continuous lines) and groundspeed (broken lines) during the same two hauls

Ground speed was calculated in those cases where the image of clear points on the bottom, e.g. small stones and pieces of shell, had been drawn out into "streaks" on the photograph by the relatively slow shutter speed. Each camera shutter was separately calibrated to give a precise time in milliseconds. The length of a sample of streaks on one photograph was measured and scaled by the white scale mark. In this way the distance that net and camera had travelled in a known time could be cal- 
culated; this is referred to as ground speed. For measurements of the speed of the net relative to the water mass, a flowmeter was attached part-way down the telephone cable by the descending divers, and readings from the surface read out unit of distance travelled, taken periodically by one of the occupants of the rubber boat.

\section{RESULTS}

Experiments were conducted during the summers of 1969 in Spey Bay $\left(57^{\circ} 41^{\prime} \mathrm{N}\right.$; $\left.03^{\circ} 03^{\prime} \mathrm{W}\right), 1970$ in Spey Bay and Sinclair Bay $\left(58^{\circ} 30^{\prime} \mathrm{N} ; 03^{\circ} 04^{\prime} \mathrm{W}\right)$ and during the summer of 1971 in Broad Bay, Isle of Lewis $\left(58^{\circ} 16^{\prime} \mathrm{N} ; 06^{\circ} 15^{\prime} \mathrm{W}\right)$. In all these areas flatfish were present in variable numbers, but the main aim was to observe haddock, particularly those from the 1967 year class. The numbers of this extremely successful brood have been estimated as some 25 times greater than average, with the result that these fish when two and three years old became relatively abundant in shallow water (I.C.E.S. 1971).

\section{Change of shape and speed of gear}

The characteristic changes in shape and speed of the seine net are the two main variables to which the behaviour of fish can be related. In Figure $2 b$ are shown two examples of change of shape. The figure shows curvature stage or wingend angle, as defined in Figure 1a, plotted against time after commencement of hauling. The diver at the centre of the headline recorded the shape of the net by referring to a small plastic "crib-board" with the curves of Figure 1a indelibly drawn on it.

The simultaneous ground and water speed measurements for these two hauls are shown in Figure 2c. It is important to note that the flowmeter readings taken every 30 seconds result in a speed value that is an integration of the variable speeds in that 30 second period. The ground speed calculated from photographs is a measure of instantaneous speed, and is therefore more variable. Haul number 70/29 J2 (Figure 2c) was carried out over an uneven stony sea-bed and the irregularity of the ground speed was caused by continuous snagging and jerking of the net. Haul number $70 /$ 6A3 (Fig. 2c) was over a more level sandy surface and shows a correspondingly smoother sequence of ground speeds.

\section{Flatfish}

The behaviour of plaice (Pleuronectes platessa) and common dab (Limanda limanda) in the present study was so similar that no distinction is made between them, and they are together referred to as "flatfish".

Flatfish were observed to be herded into the path of the net by the seine net ropes. These ropes travel in contact with or very close to the sea-bed. The fish tended to swim at right angles to the obliquely moving ropes, an orientation which is dis- 
cussed by Hemmings (1969). The right-angled movement, coupled with a strong tendency to swim away from the rope for a distance of up to $5 \mathrm{~m}$ and then either slow down or settle, resulted in a zigzag movement with respect to the rope. The fish were in this way caused to move sideways towards the net. They passed down the length of the wing in a similar fashion and were seen to accumulate in the mouth of the net in front of the groundline. The series of downward-looking photographs taken from

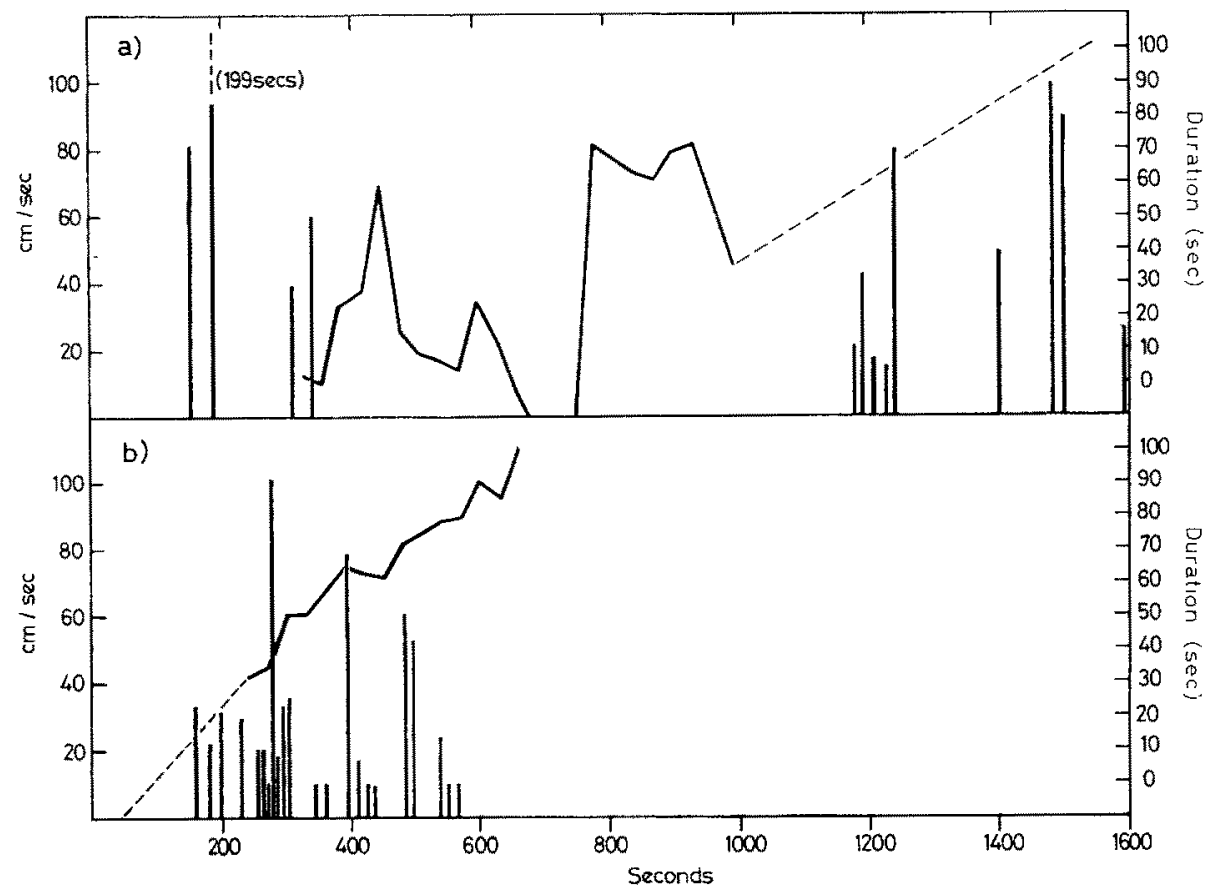

Fig. 3: Water speed of net, curve read against left ordinate. Duration of swimming of flatfish, vertical lines read against right ordinate

near the centre of the headline were used to analyse this accumulation and change in density of flatfish as the haul progressed. Figure 2 a shows the density of flatish on the two hauls in relation to the change in shape of the gear and the water and ground speeds of the net (Fig. $2 \mathrm{~b}$ and c). The rapid rise in number of flatfish in front of the groundline is typical. The zero-times of the two hauls (defined as the time when the dhan rope is placed in the coiler prior to hauling) were synchronised, but it can be seen from Figure $2 b$ that movement and subsequent change in shape occurred at slightly different times afterwards. Comparison of density and curvature for the two hauls in Figures $2 \mathrm{a}$ and $2 \mathrm{~b}$ shows that the peak density of fish corresponds to a fairly narrow stage (stage $\mathrm{B} / \mathrm{C}$ with a wingend angle of $50^{\circ}$ ) in the net curvature, and thereafter numbers of fish decline.

The tape-recordings made by divers provided data on the duration of swimming of individual fish in front of the groundline of the net. Figure 3 shows two 
examples of hauls when a number of individual fish were recorded. The duration of swimming is shown by vertical bars, and the curves show water speed of the net. During the haul shown in Figure 3a, the ropes came fast on an obstruction and were subsequently released as towing strain increased. After 1,000 seconds when the flowmeter jammed, speed increased smoothly to over $100 \mathrm{~cm} / \mathrm{sec}$.

Figure $3 \mathrm{~b}$ shows a typical smooth ground haul in which the increase of speed is gradual. One might expect that, as the speed of the gear increased, the duration of swimming in front of the groundline would decrease, but in neither example is there any close correlation between the duration of swimming and the speed at which the fish must swim to stay in front of the gear.

\section{Haddock}

There are as yet no direct observations of the herding to haddock by seine net ropes, but indirect evidence suggests that they must be effectively herded by the ropes into the path of the net. Haddock are not normally observed until well past the peak density of flatfish, when the net curvature is in stage " $C$ " or " $D$ " (Fig. 1a). If ropes longer than those indicated in Figure $1 \mathrm{~b}$ are used, haddock may appear at an earlier stage of curvature.

When haddock are first sighted they are seen swimming forwards between the wings of the net at approximately the same speed as the net. The fish were then seen gradually to lose position, or "slip back", resulting in their accumulation in front of the groundline at varying heights off the bottom. Those haddock swimming forwards less than about $1 \mathrm{~m}$ above the ground usually turned as they went back over the groundline, but those higher in the water column tended to drift back tail first, i.e. still swimming forwards but at a speed slightly less than that of the net. Fish close to the side walls of the net were frequently observed to turn in a similar way, induced to do so apparently by either the presence of conspicuous seam lines, or the junction between panels of netting of different colour.

The commonly observed behaviour pattern of keeping station with the net appears to be an optomotor response. Two experiments were designed to investigate this further. In the first, the whole of the back of the net was cut off along the seam shown in Figure 1c, leaving only the wings joined at the back end by the headline and groundline. When this net was fished in the normal way, the resulting behaviour of the haddodk was just as with the complete net; they continued to swim and eventually dropped back and escaped through the hole between the rear wingends. This showed that the fish were not in any way being "pushed" from behind, but were most probably visually fixing the wings. The second experiment consisted of removing the right wing from an otherwise complete net so the fish gathering in the mouth of the net had a visual stimulus on their left side only. In this case again behaviour appeared to be quite normal with haddock keeping station with the one left wing. When they turned back, although most went into the codend, a number swam out of the path of the net through the space where the right wing would have been. It is interesting to 
note that on occasions when fishing a complete net, a few fish outside the net were observed to swim along with it for a considerable time.

Until the technique described above of divers recording the behaviour of individual fish was introduced, the impression was formed that a large mass of haddock gathered in the mouth of the net, and that the majority of them continued to swim forwards in this position until some time was reached when they would all drop back

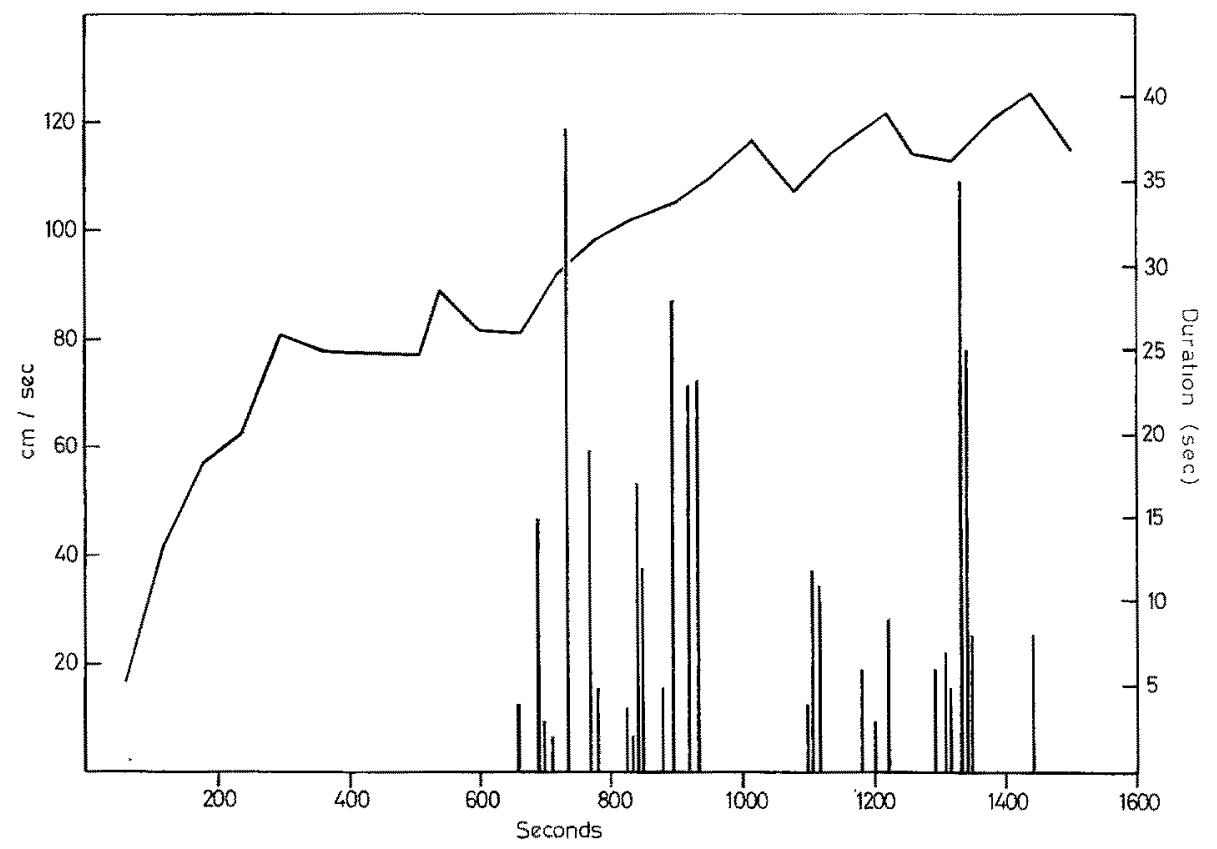

Fig. 4: Water speed of net, curve read against left ordinate. Duration of swimming of haddock, vertical lines read against right ordinate

fairly quickly, possibly due to fatigue. Using the new technique, individuals were first observed at distances up to $3 \mathrm{~m}$ in front of the net and they were followed until they passed back into it over the groundline or escaped. The results of haul number 71/ $20 S 3$ in Figure 4 show the duration of swimming of haddock in relation to the speed of the net, and it is clear that many fish swim in front of the net for only a short period time before dropping back. The impression that a mass of fish remains in front of the net for a considerable time is an illusion; there is in fact a continual interchange of fish, those at the back of the group being lost into the net, but new arrivals at the front join at a position usually outside the diver's visual range.

\section{Sandeel}

Observations on sandeels were incidental to the work on flatfish and haddock, but when sandeel schools were seen their behaviour was recorded. As it was impossible 
to pick out individuals, the results include only qualitative descriptions, generally of the movement of tight schools which, however, could be seen to separate into smaller groups and to merge into large ones almost continuously.

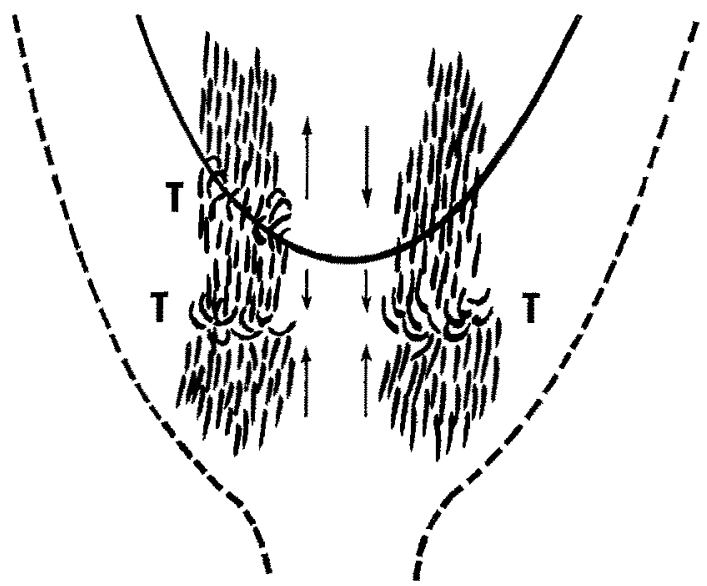

Turning zone denoted by " $T$ "

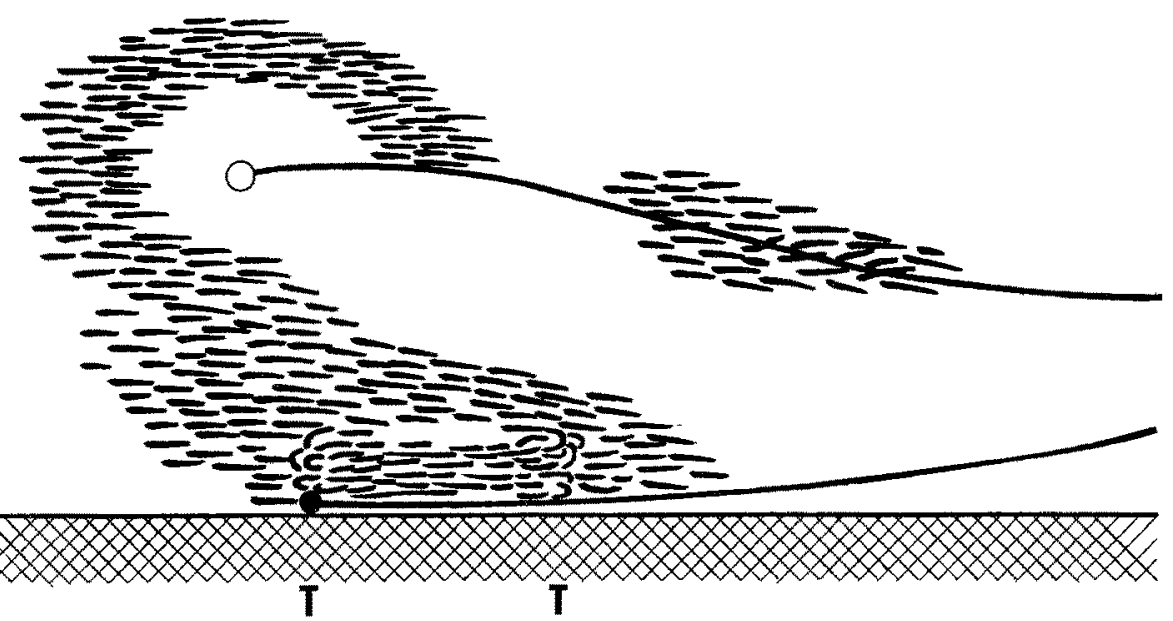

Fig. 5: Diagram of sandeel behaviour showing turning zones. Upper: Plan view of net trayelling towards top of page. Lower: Vertical section through net travelling right to left

Sandeels were seen at all heights above the bottom, from close proximity to occasions when they were in midwater and passed right over the headline. In this case it was usually only the sudden reduction in light intensity which caused observers to look up. Typical behaviour of sandeels near the net is shown in Figure 5. There was a marked avoidance of the headline, "vacuoles" being formed around it in the way that KüHLMANN \& KARST (1967) describe sandeels avoiding predators. There was little 
aversion to netting; sometimes fish inside the net would join those outside, and occasionally the reverse occurred. Sandeel behaviour near the sea-bed was interesting in being similar to that shown by haddock in these circumstances. Fish within about $1 \mathrm{~m}$ of the bottom turned over the groundline into the net, and then turned to face forwards again when 1-2 $\mathrm{m}$ back into it. Fish above $1 \mathrm{~m}$ from the bottom tended to drop back into the net without turning (Fig. 5 lower). The lett side of the plan view in Figure 5 (upper) indicates this turning effect shown by sandeels initially facing forwards, the most common situation. Occasionally a school was encountered already facing into the mouth of the net. These fish would then only turn when inside it, as shown on the right side of the plan view.

\section{DISCUSSION}

Studies of fishing gear in action are subject to a number of problems, of which perhaps the greatest is that each haul is unique. There are cyclic variables, for example, tide and time of day, plus random variables such as weather conditions and the availability of fish which individually affect results. Together these variables combine to render strict repetition of identical hauls impossible to achieve. It is therefore essential to try and record all the environmental and fishing parameters that might affect the behaviour of the fish. In terms of fish capture, the two most important factors are the speed and direction of movement of fish caused by the fishing gear. Nothing is known of the distribution of fish on the ground before fishing starts. This is a major influence on the subsequent speed and direction of movement of fish.

The sharp rise in density of flatfish in the mouth of the net at the end of curvature stage " $\mathrm{B}$ ", as shown in Figure 2a, is almost certainly the result of the ropes sweeping fish inwards from the lateral areas, the extreme corners of which are labelled " 1 " and "2" in Figure 1b. The haddock which usually appear at a rather later stage have been herded into the path of the net in the same way. However, without knowing exactly how the ropes change shape, it is impossible to calculate either the speed or direction of movement of fish situated at various points within the area enclosed by the ropes before hauling commences.

Recent studies in this laboratory have confirmed that there are two types of swimming performance in plaice and haddock: (1) at cruising speeds swimming endurance is unlimited, but the speed is limited by the oxygen supplied to an aerobic muscle system; (2) when burst swimming, high speeds can be achieved with strictly limited endurance. Speed is limited only by the frequency and power of contraction of an anaerobic muscle system, and endurance is restricted by the use of a limited quantity of available fuel, glycogen. WARDLE (1971) and WARdLE \& ANTHONY (1972) give preliminary results of this work and show that for haddock the cruising speed is 1.5 to 2 body lengths/sec, but burst speeds of up to 10 body lengths/sec are possible. Swimming at speeds higher than cruising not only reduces the endurance of fish but at least in trout alters the behaviour from "active swimming" to "seeking shelter" (BLACK 1958, BLACK et al. 1961). 
When haddock first appear between the wings of the net they are seen to be swimming in a smooth continuous fashion which may involve the use of only the aerobic muscle. As the gear speed increases to about $100 \mathrm{~cm} / \mathrm{sec}$, there are occasional bursts of faster swimming where tail beat amplitude is greater and at a higher frequency. The fish are then swimming at about 3 body lengths/sec, and these bursts of increased activity can be equated with the fish using their "fast" anaerobic musculature. It may be that the turning back of haddock into the net is the result of a behaviour change from active swimming to seeking shelter.

Field observations show that the orientation of plaice is determined by two tendencies: the first being to maintain a roughly constant angular orientation to an obliquely moving rope; the second being to swim in straight lines with angular turns at the end of each linear step. Laboratory experiments. (HEMmings, unpublished) have been conducted in the annular tank at Aberdeen in an attempt so simulate the herding of flatfish. A radial rope was arranged to sweep a circle $10 \mathrm{~m}$ in diameter at speeds that could be varied, i.e. the rope moved in the same way as the hands of a clock. The rope skimmed the sand floor of the tank in which were a number of marked plaice. The reaction of the fish was to swim along a chord of the circle, across the tank, with the result that the fish always gathered near the outer edge. The immediate conclusion was that the tendency to swim in straight lines was stronger than the tendency to show a fixed angular orientation to a moving rope. The general conclusion was that it is difficult to reproduce in the laboratory a model that adequately matches the fullscale freld situation.

The behaviour of haddock in the mouth of the net appears to be an optomotor response to the moving background formed by the wings of the net. This conclusion is supported by laboratory work using an annular optomotor apparatus with rotating backgrounds inside and outside the annulus. In this situation haddodk have been shown to have a good optomotor response (Hemmings, unpublished). Harden Jones (1963) described experiments in a similar annulus with a variety of fish species including Gadidae, but not haddodk. He showed that there is a strong tendency to keep station with the moving backgrounds of the apparatus. He later (HARDEN JoNEs 1968) discussed this and other work on the following of backgrounds by fish in the context of rheotropism or current orientation and migration. HARDEN JoNEs considered the optomotor response to be the mechanism by which fish orientate to water movements. When a fish keeps station by swimming into a water current, there is unlikely to be any relative movement between different parts of the fish's visual environment, usually the sea-bed beneath it. SHAw \& TuCKER (1965) describe an optomotor reaction of Carangidae in a cylindrical apparatus, in which a stripe pattern is followed by the fish. They consider this reaction to be a component of schooling behaviour. In schooling the fish react to a species-specific stimulus coming from the fish on either side of themselves. If then the school swims to within visual range of the substrate, there will be relative movement between two different components of the visual field, i.e. the other fish and the inanimate background. Haddock in the mouth of the seine net appear to react to the unnatural stimulus to either side of them, that is, the netting wings, and ignore the natural stimulus of the sea-bed beneath them. It may be that the turning effect shown by haddock and sandeels (Fig. 5) when near the 
bottom is to be interpreted as the fish in some way "catching sight" of the sea-bed "going the wrong way" underneath them. They respond to this by turning back over the groundline, but then immediately find themselves in a different visual situation over the moving netting floor which causes them to turn and swim forwards again.

The characteristic activities and behaviour observed when fish react to the unnatural stimuli associated with demersal seine nets and trawls seem similar in all respects to those behaviour patterns which are normally associated with reactions to natural stimuli, e.g. those of schooling and current orientation. Only in fishing methods using electricity or artificial light sources may it be necessary to describe entirely novel behaviour.

\section{SUMMARY}

1. The behaviour of flatfish, haddock and sandeels near Danish seine nets was recorded by divers using cameras and tape-recorders.

2. Flatfish swam at right angles to moving seine net ropes and collected in front of the net groundline by a zigzag process.

3. The density of flatfish in the net mouth rose sharply when the net was about half closed, and then declined more gradually.

4. The duration of swimming of flatfish was not directly related to the speed of movement of the gear.

5. Haddock were herded by the ropes and appeared near the net much later than flatfish. When in the net mouth they showed an optomotor reaction to the net wings.

6. The duration of swimming of haddock in front of the net was not directly related to its speed.

7. Sandeels avoided the headline of the net but swam through the netting. Near the sea-bed they behaved like haddock.

Acknowledgements. The work described in this paper could only have been carried out with the participation of large diving and surface support groups, whose members I thank for help and cooperation. I am also grateful to Mr. C. S. WARDLE for constructive criticism of the manuscript.

\section{LITERATURE CITED}

BLACK, E. C., 1958. Energy stores and metabolism in relation to muscular activity in fishes. In: The investigation of fish-power problems. Ed. by P. A. Larkin. Univ. Brit. Columbia, Vancouver, 51-67 (H. R. MacMillan lectures in fisheries).

- Robertson, A. C. \& PARKer, R. R., 1961. Some aspects of carbohydrate metabolism in fish. In: Comparative physiology of carbohydrate metabolism in heterothermic animals. Ed. by A. W. MARTIN. Univ. Wash. Press, Seattle, 89-122.

Harden-Jones, F. R., 1963. The reaction of fish to moving backgrounds. J. exp. Biol. 40, 437-446.

- 1968. Fish migration. Arnold, London. 325 pp.

Hemmings, C. C., 1969. Observations on the behaviour of fish during capture by the Danish 
seine net, and their relation to herding by trawl bridles. Fish. Rep. F.A.O. 62 (3), 645-655. - 1972. Diving in relation to fish behaviour problems. In: Diving applications in marine sciences research seminar. Nat. Inst. Oceanogr. Seminar Ser. 1, 48-67.

I.C.E.S. (Ed.), 1971. Preliminary report of the N. Sea roundfssh working group. The effect of recommendation 2 fisheries on the gadoid stodks. Coun. Meet. int. Coun. Explar. Sea (= C.M.-I.C.E.S.) F: 4.

Kühlmann, D. H. H. \& Karst, H., 1967. Freiwasserbeobachtungen zum Verhalten von Tobiasfischschwärmen (Ammodytidae) in der westlichen Ostsee. Z. Tierpsychol. 24, 282-297.

Shaw, E. \& Tucker, A., 1965. The optomotor reaction of schooling carangid fishes. Anim. Behav. 13, 330-336.

Thomson, D. B., 1969. The seine net - its origin, evolution and use. Fishing News Books, London, $192 \mathrm{pp}$.

WARDLE, C. S., 1971. An assessment of the role of lactic acid as a limit to fish performance during capture. Coun. Meet. int. Coun. Explor. Sea (= C.M.-I.C.E.S.) B 18.

- \& Anthony, P. D., 1972. A new technique for measurement of fish burst speed and for the assessment of the shyness of fish to intruding nets and ropes. Coun. Meet. int. Coun. Explor. Sea (= C.M.-I.C.E.S.) B 17.

Author's address: Dr. C. C. Hemmings

Marine Laboratory

Victoria Road

Aberdeen

Scotland 